\title{
WHO enters new terrain in Ebola research
}

$\mathrm{T}$ he meeting on unproven interventions for Ebola at the World Health Organization on Sept. 4 and 5 takes the global agency into "absolutely uncharted territory," says WHO spokesperson, Dr. Margaret Harris.

"We're actually often criticized for being incredibly slow about saying, 'Do this over that', because we demand enormous levels of evidence," she says. But for Ebola virus disease, there are no approved therapies, so WHO is attempting to move investigational interventions forward, including medications, vaccines and so-called convalescent serum, made from the blood of survivors.

The Sept. 4 meeting, aimed at guiding research in the midst of the outbreak, marks a sharp turn for WHO, where research efforts are viewed as fragmented. About five years ago, WHO eliminated its office of research strategy; the department leading the Ebola research effort, known as Knowledge, Ethics and Research, was only formed at the end of 2013. But the Ebola crisis forced a change. Says Harris, "We're in a desperate situation, where people are dying in numbers that are far too high and there is no specific treatment to offer them."

In August, WHO convened an ad hoc ethics panel to advise on the use of investigational drugs — such as the experimental cocktail of monoclonal antibodies known as ZMapp, which has been given to seven patients. The panel concluded that given the circumstances it is ethical to offer unregistered drugs, but the drugs must be evaluated "in the best possible clinical trials under the circumstances" and there is a moral obligation to "collect and share all data generated."

In the weeks since then, the crisis has worsened. WHO now says that the caseload of those infected "could exceed 20000 over the course of this emergency"; scientists put the case fatality rate of the current Ebola out-

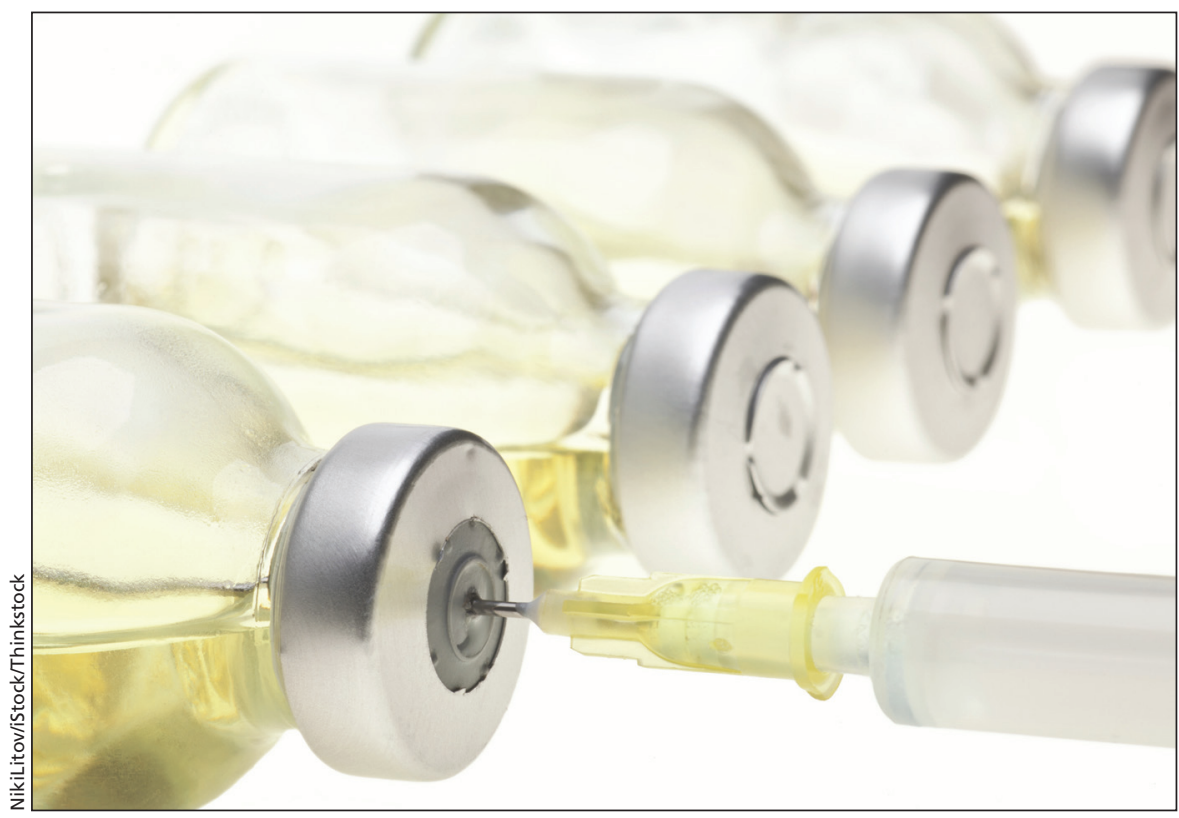

In the absence of approved therapies for patients diagnosed with Ebola, WHO is taking the unprecedented step of attempting to move research forward.

break at $78 \%$, and in late August the disease spread to another country Senegal - and another city - Port Harcourt, Nigeria, the hub of Nigeria's oil and gas industry, where Canadian oil executives travel regularly.

In this urgent context, hundreds of scientists, company representatives, ethicists and drug regulatory officials from Health Canada, the FDA and Europe's EMEA along with representatives from nongovernmental organizations, and health officials and community leaders from areas affected by Ebola, are in Geneva to consider "what's viable and what's not, what's feasible and what's not," Harris says.

Technical presentations are slated for Sept. 4. Dr. Gary Kobinger of the Public Health Agency of Canada (PHAC) and the National Microbiology Laboratory in Winnipeg will attend and may describe the preclinical work his team published in Nature Aug. 29, showing that ZMapp is effective in primates. The Canadian team infected 21 monkeys with Ebola virus and gave 18 of the animals ZMapp at different times. The treated monkeys all lived while the three control animals died. Five of the seven people treated with ZMapp have survived, but it is unclear if the medication helped them to recover and it will be months before there is more ZMapp available.

PHAC is also represented by Dr. Tom Wong, director, Influenza and other Respiratory Infectious Disease Division, and Dr. Theresa Tam, branch head, Health Security Infrastructure Branch. Dr. Lindsay Elmgren, director, Centre of Biologics Evaluation is attending on behalf of Health Canada.

The University of Toronto's Dr. Eleanor Fish, who may also present Sept. 4, advocates treating Ebola patients with a form of interferon alpha, a treatment that was beneficial when used to treat patients with SARS at Toronto's North York General Hospital during the 2003 outbreak. In an email to $C M A J$, Fish said that that she believes interferon should be "seriously considered" for use soon after a person has been exposed to Ebola because it could possibly reduce viremia, allowing supportive care and other therapies to be more effective. 
Although Fish hopes "there will be a consensus to move forward with a pilot evaluation" of interferon, Thomas Geisbert, an Ebola expert at the University of Texas Medical Branch in Galveston, is critical of the idea. In an e-mail to $C M A J$, he said that when tested in monkeys, some interferons "actually made things worse where the treated animals died faster than the untreated controls." His preference is to test the therapies "proven to be the most effective in nonhuman primates," such as ZMapp.

Yet for some observers, including Jim Lavery, a global research expert at St. Michael's Hospital in Toronto, doing any clinical trial in a hospital treating
Ebola patients is worrisome. Given how demanding trials are, Lavery fears that "the proper focus on public health and clinical issues could easily be overrun by a lot of the real nuances that have to be managed at research sites."

These sorts of dilemma will be discussed at a session devoted to development of an ethics framework, where the WHO's ethics advisory panel will present a more thorough guidance document including contributions by panel member and University of Toronto public health researcher, Dr. Ross Upshur. Upshur, a highly sought expert on the ethical issues that arise during pandemics, told CMAJ by email that he's found his work on Ebola "exhaust- ing, as it is terra incognito and the outbreak is out of control."

The lack of research on how to treat Ebola has already captured the attention of research funders. On Aug. 21, the London-based Wellcome Trust and the UK's Department for International Development announced a joint request for Ebola research proposals, placing 6.5 million British pounds on the table with an application deadline of Sept. 8. Upshur suspects that a consortium, possibly involving these sponsors, will be formed to provide overall leadership for the Ebola research initiative. Miriam Shuchman, Toronto, Ont.

CMAJ 2014. DOI:10.1503/cmaj.109-4893 